\title{
Chronic total occlusion percutaneous coronary intervention in everyday clinical practice - an expert opinion of the Association of Cardiovascular Interventions of the Polish Cardiac Society
}

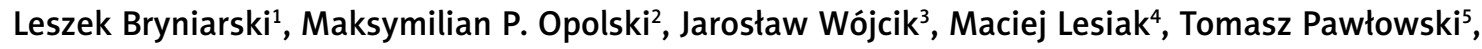

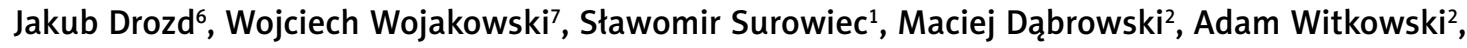 \\ Dariusz Dudek ${ }^{1}$, Marek Grygier ${ }^{4}$, Stanisław Bartuś ${ }^{1}$
}

\begin{abstract}
${ }^{1}$ Second Department of Cardiology, Institute of Cardiology, Jagiellonian University Medical College, Krakow, Poland 2Department of Interventional Cardiology and Angiology, National Institute of Cardiology, Warsaw, Poland ${ }^{3}$ Hospital of Invasive Cardiology IKARDIA, Lublin/Nałęczów, Poland ${ }^{4}$ First Department of Cardiology, Poznan University of Medical Sciences, Poznan, Poland ${ }^{5}$ Department of Invasive Cardiology, Centre of Postgraduate Medical Education, Warsaw, Poland ${ }^{6}$ Department of Cardiology, SP ZOZ MSWiA, Lublin, Poland

${ }^{7}$ Department of Cardiology and Structural Heart Diseases, Medical University of Silesia, Katowice, Poland
\end{abstract}

Adv Interv Cardiol 2021; 17, 1 (63): 6-20 DOI: https://doi.org/10.5114/aic.2021.104763

\begin{abstract}
A bstract
Coronary chronic total occlusions (CTO) are increasingly encountered during invasive and non-invasive coronary angiography and remain the most challenging lesions for percutaneous revascularization. During recent years success rates and safety outcomes of CTO percutaneous coronary intervention ( $\mathrm{PCl}$ ) have substantially improved, particularly due to the introduction of new techniques and dedicated equipment as well as specialized training programs of CTO operators. Significantly, the steady advances in CTO PCI techniques have coincided with the new data from randomized clinical trials supporting the role of percutaneous recanalization of CTO in relieving angina and improving the quality of life. The current expert consensus document outlines the rationale, clinical outcomes as well as technical, safety and reimbursement issues of $\mathrm{CTO} \mathrm{PCl}$. In addition, the requirements for achieving and maintaining competency in $\mathrm{CTO} \mathrm{PCl}$ among interventional cardiologists are discussed. Finally, we present the modified hybrid algorithm (the so-called Polish hybrid algorithm) providing some unique refinements to the contemporary CTO PCI strategies. Continuous efforts (including active engagement with the payer) are urgently needed to increase guideline-recommended referrals to $\mathrm{CTO} \mathrm{PCI}$, and thus improve the quality of life of CTO patients in Poland.
\end{abstract}

Key words: coronary chronic total occlusion, percutaneous coronary intervention, hybrid algorithm.

Su m m a ry

Coronary chronic total occlusions (СTO) are increasingly encountered during invasive and non-invasive coronary angiography and remain the most challenging lesions for percutaneous coronary intervention ( $\mathrm{PCl}$ ). During recent years success rates and safety outcomes of CTO PCI have substantially improved, and successful recanalization of CTO has been shown to relief angina and improve the quality of life based on randomized clinical trial data. Nevertheless, and contrary to the Western European countries, CTO PCI is significantly underused and accounts for $<3 \%$ of all PCl in Poland. The current expert consensus summarizes the rationale, clinical outcomes as well as technical and safety issues of CTO PCI. Significantly, we have presented the modified hybrid algorithm (the "so called" Polish hybrid algorithm) providing some unique refinements to the contemporary CTO PCI strategies. Finally, the list of succinct and practical recommendations on CTO PCI has been provided. Continuous efforts are urgently needed to expand the knowledge on CTO PCI and close the gap between Poland and Western European countries.

\section{Corresponding author:}

Maksymilian P. Opolski MD, PhD, Department of Interventional Cardiology and Angiology, National Institute of Cardiology, 42 Alpejska St, 04-628 Warsaw, Poland, phone: +48 501444 303, fax: +48 2261338 19, e-mail: mopolski@ikard.pl

Received: 5.01.2021, accepted: 9.01.2021. 


\section{Introduction}

During recent years success rates and safety of percutaneous coronary intervention $(\mathrm{PCl})$ in chronic total occlusion (CTO) have substantially improved, particularly due to the introduction of new techniques and dedicated equipment as well as specialized training programs of CTO operators. Development of new wires and microcatheters, refinement of retrograde and hybrid techniques as well as periprocedural guidance using invasive and non-invasive imaging tools allowed to achieve success rates exceeding $90 \%$ in luminary centers with highly experienced CTO operators [1-3]. The current consensus document summarizes contemporary data on CTO PCI including up-to-date recommendations of the EuroCTO Club, Global Consensus and Polish experts opinions to help disseminate the latest knowledge and recommendations among practicing physicians [4, 5].

Coronary CTO is still the last barrier to complete percutaneous revascularization of patients with coronary artery disease. The presence of CTO, defined as an angiographic finding of complete occlusion of a coronary vessel of more than 3 months duration, is a common finding during routine coronary angiography, with a prevalence between $18 \%$ and $52 \%$ [6-11]. Despite high frequency of severe ischemia and angina resistant to medical therapy in most patients with CTO, the rate of attempted CTO $\mathrm{PCl}$ is low and averages $10 \%$, with the Canadian multicenter registry showing wide variability in attempt rates ranging between 1 and 16\% across different centers [11]. Based on the unpublished data from the Polish nationwide registry (ORPKI) on 535,857 patients treated with PCI between 2014 and 2018, only 12,572 (2.3\%) patients underwent CTO PCl. This implies that patients selected for CTO PCl are often chosen according to the operator's subjective opinion rather than the actual clinical need. Still, it is not uncommon for certain centers that patients with clear indication for revascularization are denied CTO $\mathrm{PCl}$ because of the absence of skills, tools or concerns in terms of the potential complications as well as non-adequate financial support of CTO procedures by the National Health Fund in Poland. At the other extreme, patients with simple CTO lesions, but no clear clinical indication for revascularization, are referred for CTO PCI. The lack of appropriate knowledge about the potential clinical benefits of $\mathrm{CTO} \mathrm{PCl}$, which is undeniably a more complex procedure with higher costs than the regular PCI of non-CTO lesions, has led to reluctance to refer these patients for percutaneous revascularization from the wider cardiology community [12].

\section{Indications}

Currently there is a modest level of evidence for the most optimal treatment of CTO. Significantly, patients with CTO lesions appropriate for intervention are those who are symptomatic (including both angina and/or dys- pnea) despite optimal medical therapy (OMT). Hence, the European Society of Cardiology (ESC) guidelines assign CTO PCl a class Ila indication, whereby percutaneous revascularization of СTO should be considered in patients with angina resistant to medical therapy or with a large area of documented ischemia in the territory of the occluded vessel [13-19]. At the same time the authors of the ESC guidelines affirm that "broadly speaking, the treatment of CTO may be considered analogous to the treatment of non-CTO lesions" [13]. In addition, it is recommended that complex СTO procedures are only performed by adequately experienced interventionalists (class Ila, level of evidence C). However, there is ambiguity in the definitions of appropriate indications as well as sufficient "operator expertise". In our opinion, $\mathrm{PCl}$ should be equally indicated in a patient with CTO (currently class Ila) as compared to a patient with a non-occlusive critical coronary stenosis (currently class I), provided that both lesions induce the same level of ischemia and symptoms.

Two recently published randomized controlled clinical trials and several observational studies reported symptoms improvement after successful CTO PCI $[14,20]$. The EUROCTO trial randomized 396 patients in a $2: 1$ fashion to CTO PCl plus OMT or OMT alone. Significantly, all non-CTO lesions were treated before randomization to assign the intrinsic effect of revascularization to CTO. The success rate of CTO recanalization was $87 \%$, and the trial showed superiority of $\mathrm{PCl}$ over OMT for angina frequency and quality of life at 12 months follow-up. In addition, physical limitation and functional angina class also improved in the CTO PCI arm [14]. The IMPACTOR-CTO trial included 94 patients with isolated CTO of the RCA and showed a significant decrease of ischemia burden as well as improvement of functional status and quality of life in the CTO PCI group versus the OMT group [20].

In contrast, two randomized controlled clinical trials showed neutral effects of CTO PCI. The EXPLORE trial randomized 304 patients after PCI for ST-segment elevation myocardial infarction (STEMI) to subsequent $\mathrm{PCl}$ or OMT for concomitant CTO. The primary endpoints were defined as left ventricular ejection fraction and left ventricular end-diastolic volume assessed by cardiac magnetic resonance at 4 months follow-up. Although the trial was negative, some methodological flaws (including slow recruitment and site volume with the mean of 2.4 patients/year/center, relatively low CTO $\mathrm{PCl}$ success rate of $73 \%$, high crossover rate of $23 \%$, and finally the lack of inducible myocardial ischemia test before $\mathrm{PCI}$ ) might have influenced the results [21]. In lieu of these findings, the authors found that there were more patients with freedom from angina after CTO PCI at 1-year follow-up [22]. Another negative trial was the DECISION CTO trial, in which 834 patients were allocated to either CTO PCI or no CTO PCl. After 4.0 years of follow-up, there was no significant difference between the CTO-PCI and the no 
CTO-PCI strategies in the incidence of death, myocardial infarction, stroke, or any revascularization [23]. Nevertheless, the DECISION CTO trial was widely criticized due to its design (revascularization of non-CTO lesions was allowed in both groups and observed in more than $70 \%$ of patients, extremely low enrolment rate, $18 \%$ crossover rate, inclusion of all-cause death and stroke in the primary endpoint), and based on our opinion should not be taken into consideration when interpreting the potential benefits of CTO PCI [24].

In observational studies $\mathrm{CTO} \mathrm{PCl}$ relieved regional ischemia and was associated with improved exercise capacity, increased anaerobic threshold, and fewer depressive symptoms [25-29]. Subsequently, it was proven that viable myocardium supplied by a CTO is a persistently ischemic zone $[30,31]$. Both regional and global left ventricular function improved after successful CTO PCI in patients with viability or baseline dysfunction [32]. This result was, however, not confirmed in two randomized controlled trials [21, 33]. Nevertheless, these randomized studies were performed in patients with preserved left ventricular function, did not examine the presence of viable and dysfunctional myocardium, nor did they assess exercise induced changes in left ventricular function. Also, patients with a coronary СTO who received an implantable cardioverter defibrillator for primary or secondary prevention had a higher risk for ventricular arrhythmias as well as higher frequency of recurrent ventricular tachycardia after ablation than patients with non-occlusive coronary stenoses [34-36]. However, there are no randomized studies assessing whether CTO PCI may reduce the risk for subsequent arrhythmias. Importantly, in observational studies, patients presenting with acute $\mathrm{MI}$ (including both STEMI and non-STEMI) and a CTO in a non-culprit coronary artery had a higher risk of worse clinical outcomes as compared with patients without a CTO [37-39]. Also, a meta-analysis of
6 studies including 1253 patients showed that CTO PCI of the non-infarct-related artery in patients presenting with STEMI was associated with a significant reduction in major adverse cardiac events (MACE), cardiovascular mortality, and heart failure readmission [40].

In a meta-analysis of 25 observational studies comparing successful vs. failed CTO PCl, patients with a successful procedure had lower mortality [30]. Moreover, observational studies demonstrated a lower incidence of MACE after successful CTO PCI as compared with OMT alone irrespective of the quality of the collateral circulation [9, 41, 42]. Although CTO PCI might improve hard clinical outcomes, particularly among patients with a large ischemic burden (e.g. ischemia of $>10 \%$ of the myocardium) in whom complete revascularization is achieved [43-47], this hypothesis still requires confirmation in a well-designed, prospective, randomized clinical trial.

The belief that all CTO lesions are benign is likely unsubstantiated, and there are situations where intervention is highly indicated. Hence, a patient with CTO requires comprehensive assessment of symptoms (including arrhythmia), left ventricular function, ischemia, and/ or viability prior to revascularization (Figure 1). In case of persisting angina and/or exertional dyspnea unrelated to other conditions (i.e. anemia or chronic obstructive pulmonary disease) and preserved left ventricular function, a high burden of ischemia is almost always present, and the referral for CTO PCI should be considered after meticulous assessment of the risk to benefit ratio.

Of note, the decision to embark on CTO PCI should be discussed within the broader group of physicians including the physician in charge, non-invasive cardiologist and invasive cardiologist trained in CTO PCI. Equally important is a thorough discussion between a physician and a patient about the course and the length of the procedure, its potential complications as well as the expected clinical benefit.

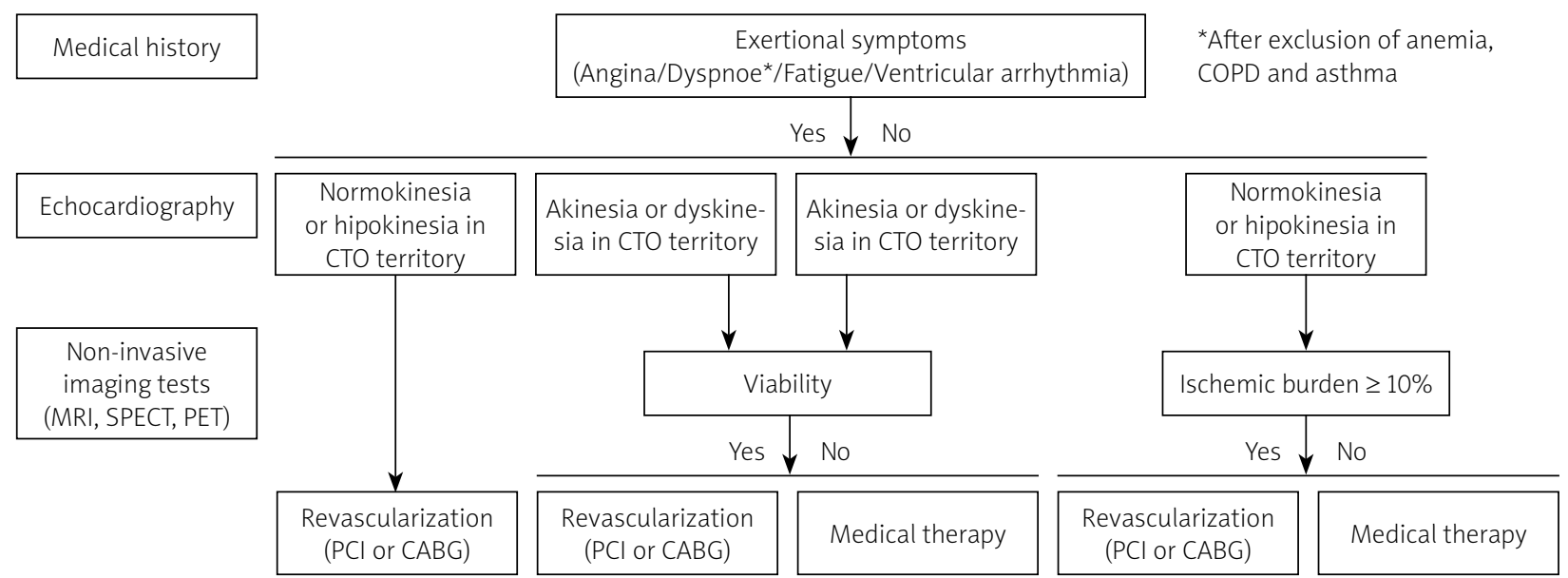

Figure 1. Indications for CTO PCl according to symptoms, ischemia, and viability CTO - chronic total occlusion, $\mathrm{PCl}$ - percutaneous coronary intervention. 


\section{Angiogram analysis}

CTO $\mathrm{PCl}$ requires meticulous preparation. The first step includes careful and structured review of the angiogram, and also, if available, coronary computed tomography angiography (coronary CTA) [4]. It is generally discouraged to perform ad-hoc CTO PCl after diagnostic angiography so as to leave sufficient time for angiogram analysis, planning the procedure, and preparation of the availability of the catheterization laboratory as well as the whole team involved in the procedure. It is recommended to routinely perform dual catheter injection unless retrograde filling of CTO is absent via the donor artery [4]. Such an approach allows for better visualization and appreciation of CTO anatomy and prevents repetitive antegrade injections with increased risk of dissections during guidewire manipulation. According to the EuroCTO Club database, on average $75 \%$ of all CTO PCI are performed with dual catheter injection [5]. The review of angiogram should focus on 4 crucial CTO characteristics: 1) proximal cap morphology; 2) occlusion length, course and composition (visible calcium), 3) quality of distal vessel and distal cap morphology, 4) characteristics of the collateral circulation. Below we present the main rationale for the assessment of each of the above-mentioned angiographic characteristics:

- Determination of the morphology of the proximal cap is crucial for selection of the most optimal approach antegrade in case of a well-defined cap or retrograde in case of proximal cap ambiguity. Alternatively, additional imaging tools - such as intravascular ultrasound (IVUS) or coronary CTA (in selected cases with CT co-registration availability) or less often selective contrast injection via the microcatheter - can be employed for clarifying proximal cap ambiguity.

- Lesion length can be accurately assessed by dual injection or coronary CTA. Both coronary calcification and vessel tortuosity can be better determined by coronary CTA than invasive angiography.

- Distal vessel size as well as the presence of residual coronary artery disease and bifurcation at the distal cap should be routinely evaluated to gauge the chances of success in antegrade dissection and re-entry (ADR) technique.

- Evaluation of collaterals is essential for deciding on a retrograde approach and should be obtained with high-quality angiography (optimally during breath hold and without panning) in different projections. Collateral size, tortuosity, bifurcations, entry and exit angles, as well as the distance from the collateral exit to the distal cap must be assessed. Lack of tortuosity and the optimal size increase the chances of successful guidewire crossing. Currently, the Werner classification is used to assess the quality of collaterals (CCO - no continuous connection, CC1 - threadlike connection, CC2 - side branch-like connection) [48]. Selec- tive contrast tip injection through a microcatheter using a 2 to $3 \mathrm{ml}$ syringe can allow proper visualization of the collateral pathway. Septal collaterals are usually safe and relatively easy to cross using soft tip guidewires and can be dilated using small profile balloons in case of difficulty in microcatheter passage. The epicardial pathway should be reserved for very experienced $\mathrm{PCl}$ operators in adequately equipped centers prepared to treat epicardial collateral perforation with coils or other techniques (selective fat embolization, thrombin injection).

\section{CTO scores}

Currently, there is a large number of scores (including angiographic, computed tomographic and clinical parameters) which were developed to estimate the difficulty level of CTO. The historically first and most used scoring system is the relatively simple J-CTO score, which was originally validated to estimate the likelihood of successful and time-efficient (within $30 \mathrm{~min}$ ) antegrade wire crossing. The J-CTO score is based on 5 variables: blunt proximal cap, bending $>45^{\circ}$ within the CTO segment, occlusion length $\geq 20 \mathrm{~mm}$, visible calcification, and previously failed attempt $[48,49]$. Each present parameter is assigned one point and all points are summed to calculate the total J-CTO score and stratify lesion difficulty as: easy (J-CTO score of 0 ), intermediate (J-CTO score of 1 ), difficult (J-CTO score of 2), and very difficult (J-CTO score $>3$ points). In addition, the J-CTO score has been validated to predict 1-year target lesion revascularization after successful CTO PCI [50]. Other angiographic scores to predict technical success of CTO PCI include: PROGRESS-CTO score [51], RECHARGE registry score [52], CL-score [53], ORA score [54], Ellis score [55], W-CTO score [56] and CASTLE score [57]. Also, it is endorsed to assess the risk of periprocedural complications by using the PROGRES CTO Complications Score [58].

Besides angiographic scores, coronary CTA-based scoring systems, including the CT-RECTOR score (Computed Tomography Registry of Chronic Total Occlusion Revascularization) [59] and the KKCT score (Korean Multicenter CTO CT registry score) [60], were developed. Noteworthy, both of these scores have superior diagnostic accuracy as compared with the angiographic J-CTO score for prediction of time-efficient guidewire crossing and final procedural success. Although coronary CTA is still rarely applied for planning and periprocedural guidance of $\mathrm{CTO} \mathrm{PCl}$, it surpasses invasive angiography for visualization of calcification, proximal cap ambiguity, tortuosity, and distal CTO segment [61]. Consequently, coronary CTA is particularly useful for guiding PCI in CTO lesions with poor visualization on invasive angiography such as long CTO, ostial occlusions, CTO in patients after coronary artery bypass grafting and previously failed CTO $\mathrm{PCl}$. In addition, 3-dimensional CTA can be displayed and 
automatically aligned with the fluoroscopic C-arm in the catheterization laboratory so as to aid in: 1 ) selection of the most optimal angiographic projection with the least vessel foreshortening; 2) clarification of proximal cap ambiguity; 3) navigation of guidewire crossing along the occlusion site; and 4) facilitating the most optimal re-entry site in dissection and re-entry techniques. Currently, the wider application of coronary CTA for guiding CTO PCI is limited to a few luminary centers with availability of advanced angiography systems with in-built CT applications.

\section{Access site}

The choice of arterial access depends on the clinical situation and operator preference and can include various sites: bifemoral, biradial, radial and femoral, and least often two ipsilateral femoral sheaths. When choosing the femoral approach, it is advocated to use long (35 to $45 \mathrm{~cm}$ ) and armed $7 \mathrm{Fr}$ or $8 \mathrm{Fr}$ sheaths. Although some operators prefer the radial approach (commonly using slender $7 \mathrm{Fr}$ sheaths or less often regular $6 \mathrm{Fr}$ sheaths) over the femoral approach, the benefit of reducing access site complications should be balanced against lesser supportive power of the smaller guiding catheters [62]. Hence, the radial approach for the donor artery and the femoral approach for the CTO vessel are frequently regarded as the most optimal solution for maintaining optimal support and reduction of arterial access complications.

\section{Guiding catheters}

CTO $\mathrm{PCl}$ requires optimal guiding catheter support (both passive and active) with coaxial alignment, and an adequately large lumen to host additional devices [5]. It is advised to use guiding catheters with side holes to prevent dissections unless ADR technique is contemplated as the most likely strategy. Most operators use $7 \mathrm{Fr}$ guides or $8 \mathrm{Fr}$ guides for the CTO vessel, and $7 \mathrm{Fr}$ guides or $6 \mathrm{Fr}$ guides for contralateral injection. For the left coronary artery extra backup guides (EBU) are preferred, although in some situations (such as CTO of the circumflex artery) the Amplatz guide can be advantageous. For the right coronary artery the Amplatz left guide is preferred as the most supportive guiding catheter, with other guides being used in specific anatomic situations (Judkins, Amplatz right, RBU, IMA, 3D RC, shepherd's crook, hockey stick curves). The CTO PCl operators should be familiar with balloon anchoring and mother-in-child techniques.

\section{Guidewires}

During recent years substantial progress in guidewire technology has been achieved allowing for increased success rates of CTO recanalization despite growing lesion complexity [5]. Expertise in the composition and properties of the guidewires is mandatory for CTO $\mathrm{PCl}$ operators. Generally, guidewires can be divided into 3 categories according to the stiffness of its tip: soft ( $\leq 1 \mathrm{gr}$ ), intermediate ( $2-6 \mathrm{gr}$ ) and stiff (>9 gr). Soft tapered polymeric composite core wires are intended for soft tissue tracking (passive wire control), intermediate tapered composite core guidewires are mostly applied for hard tissue tracking (active wire control), whereas stiff tapered wires are designed for calcified tissue penetration including highly resistant proximal cap crossing. In the current era, Fielder family wires (Asahi Intecc, Nagoya, Japan) including Fielder XT, XT-R and XT-A are mostly used for soft tissue tracking. In contrast, for active wiring (called the "deflection and rotation" technique) the Gaia family (Asahi Intecc, Nagoya, Japan) is preferred. The most commonly used stiff wires with high tipload/ penetration force include Confianza Pro 12 (Asahi Intecc, Nagoya, Japan) and Hornet 14 (Boston Scientific, Marlborough, MA, USA). For the retrograde approach and collateral crossing, the preferred guidewires include Sion, Sion Black, Suoh 3 and Fielder XT-R (all Asahi Intecc, Nagoya, Japan). Subintimal tracking using the knuckle wire technique is usually performed with polymer jacketed guidewires such as Fielder XT or Fielder XT-A (both Asahi Intecc, Nagoya, Japan), Pilot 200 (Abbott Vascular, USA) or Fighter (Boston Scientific, Marlborough, MA, USA). Recently, the dedicated polymer jacketed and hydrophilic coating knuckle wire Gladius Mongo (Asahi Intecc, Nagoya, Japan) with increased lubrication and torque transmission has been introduced. An overview of currently available guidewires is presented in Table I.

\section{Microcatheters}

Microcatheters allow for safe delivery, enhanced navigation with adequate support and quick replacement of the guidewires and are essential for procedural success of CTO PCI [4, 5]. Specifically, the distance between the tip of the microcatheter and the СТO entry site can alter the penetration force, and thus the mechanical properties of the guidewire. Moreover, microcatheters allow not only for rapid exchange but also for multiple tip reshaping of the guidewires. Ultimately, following successful guidewire CTO crossing, microcatheters are advanced to the distal СTO segment beyond the occlusion site, enabling lesion dilatation and modification. In retrograde technique, microcatheters dilate collaterals channels and protect them from wire-induced trauma. In specific anatomic situations (parallel wire technique, side branch at proximal cap, bifurcation, wiring of difficult collaterals) dual lumen microcatheters can be successfully employed. Microcatheter selection depends on CTO angiographic characteristics, operator's preference, and local availability. In contrast, over-the-wire balloons (still utilized by some operators due to financial constraints) are hampered by significant limitations (including difficulty 
Table I. An overview of CTO guidewires

\begin{tabular}{|c|c|c|c|c|}
\hline Company & Guidewire & Tip stiffness [g] & Polymeric & Hydrophilic tip \\
\hline \multirow[t]{15}{*}{ Abbott Vascular } & Whisper LS & 0.8 & Yes & Yes \\
\hline & Whisper MS & 1.0 & Yes & Yes \\
\hline & Whisper ES & 1.2 & Yes & Yes \\
\hline & PILOT 50 & 1.5 & Yes & Yes \\
\hline & PILOT 150 & 2.7 & Yes & Yes \\
\hline & PILOT 200 & 4.1 & Yes & Yes \\
\hline & Cross-It 100 & 1.7 & No & No \\
\hline & Cross-It 200 & 3 & No & No \\
\hline & Cross-It 300 & 4 & No & No \\
\hline & Cross-It 400 & 6 & No & No \\
\hline & Progress 40 & 4.8 & No & No \\
\hline & Progress 80 & 9.7 & No & No \\
\hline & Progress 120 & 13.9 & No & No \\
\hline & Progress 140T & 12.5 & No & No \\
\hline & Progress 200T & 13.9 & No & No \\
\hline \multirow[t]{24}{*}{ Asahi Intecc } & SION & 0.7 & No & Yes \\
\hline & SION blue & 0.5 & No & No \\
\hline & SION blue ES & 0.5 & No & No \\
\hline & SION black & 0.8 & Yes & Yes \\
\hline & SUOH 0.3 & 0.3 & Yes & Yes \\
\hline & Fielder FC & 0.8 & Yes & Yes \\
\hline & Fielder XT & 0.8 & Yes & Yes \\
\hline & Fielder XT-A & 1.0 & Yes & Yes \\
\hline & Fielder XT-R & 0.6 & Yes & Yes \\
\hline & Gladius & 3 & Yes & Yes \\
\hline & Gladius Mongo & 3 & Yes & Yes \\
\hline & Gaia First & 1.7 & No & Yes \\
\hline & Gaia Second & 3.5 & No & Yes \\
\hline & Gaia Third & 4.5 & No & Yes \\
\hline & Gaia Next 1 & 2 & No & Yes \\
\hline & Gaia Next 2 & 4 & No & Yes \\
\hline & Gaia Next 3 & 6 & No & Yes \\
\hline & MIRACLEbros & 3,6 and 12 & No & No \\
\hline & ULTIMATEbros 3 & 3 & No & No \\
\hline & Confianza & 9 & No & No \\
\hline & Confianza Pro & 9,12 and 20 & No & No \\
\hline & Astato XS 20 and 40 & 20 and 40 & No & No \\
\hline & Astato 30 & 30 & No & No \\
\hline & RG3 & 3 & No & Yes \\
\hline \multirow[t]{6}{*}{ Boston Scientific } & Samurai & 0.5 & No & Yes \\
\hline & Samurai RC & 0.5 & No & Yes \\
\hline & Fighter & 1.2 & Yes & Yes \\
\hline & Hornet & 1 & No & Yes \\
\hline & Hornet 10 & 10 & No & Yes \\
\hline & Hornet 14 & 14 & No & Yes \\
\hline \multirow[t]{2}{*}{ Cordis/J\&J } & Shinobi & 7 & Yes & Yes \\
\hline & Shinobi Plus & 6.8 & Yes & Yes \\
\hline \multirow[t]{2}{*}{ Medtronic } & Persuader 3 and 6 & 3 and 6 & No & Yes \\
\hline & Persuader 9 & 9 & No & Yes \\
\hline \multirow[t]{6}{*}{ Terumo } & Runthrough NS Floppy & 1 & No & Yes \\
\hline & Runthrough NS Hypercoat & 1 & Yes & Yes \\
\hline & Runthrough NS Intermediate & 3.6 & No & Yes \\
\hline & Crosswire NT & 7.7 & No & Yes \\
\hline & Crosswire Hard type 40 & 15.6 & No & Yes \\
\hline & Crosswire Hard type 80 & 26.7 & No & Yes \\
\hline
\end{tabular}


in precise location of the tip, inefficient balloon advancement, and tendency to kink), and should not be routinely used in CTO PCI. In Table II the key characteristics of microcatheters used for $\mathrm{CTO} \mathrm{PCl}$ are presented.

\section{CTO PCI techniques and hybrid algorithm}

The main strategies in CTO PCl are classified as follows: 1) antegrade wire escalation, 2) ADR, 3) retrograde wire escalation, and 4) retrograde dissection and re-entry $[4,5]$.

Antegrade wire escalation is the most common initial CTO PCI strategy [2, 63-65]. It is based on different wires' properties that are used according to СTO characteristics: (tapered stump or visible channels - polymer-jacketed low penetration force guidewires; blunt stump - intermediate and high penetration guidewires; highly resistant cap - high penetration guidewires). In each case escalation and de-escalation strategies are recommended depending on the particular situation. In case of subintimal tracking, parallel wire technique (optimally assisted by dual lumen microcatheter) can be implemented to avoid enlargement of the subintimal space [5]. Alternatively, ADR technique can be applied.

ADR technique can be either used as a first-choice CTO PCl strategy or in case of failed antegrade wiring or retrograde techniques [66]. The main concept of ADR is to enter the subintimal space, cross the occlusion site, and ultimately re-enter into the distal true lumen. The historically first ADR technique, called subintimal tracking and re-entry (STAR), is fully uncontrollable and can result in unnecessary stenting of long vessel segments with potentially higher risk for loss of the side branches and subsequent re-occlusion [67-69]. It was thus subsequently replaced with the "investment procedure" relying on subintimal plaque modification (using balloon predilatation) with delayed stenting for enhanced chances of antegrade wiring during repeat procedure [70, 71]. In contrast, the modern ADR relies on the application of dedicated re-entry systems such as the CrossBoss catheter and the Stingray balloon (both Boston Scientific, Marlborough, MA, USA) to minimize vascular injury, limit the length of the dissection and stenting segment, and, to some extent, preserve the side branches, leading to favorable clinical outcomes [72-75]. In addition, many other dissection techniques were developed to achieve successful re-entry into the true distal lumen (miniSTAR [76], limited antegrade subintimal tracking [77]) or penetrate the proximal cap (scratch and go, balloon assisted subintimal entry or Carlino [78]). Of particular interest, recently a novel and relatively simple ADR technique,

Table II. An overview of coronary microcatheters

\begin{tabular}{|c|c|c|c|c|}
\hline Company & Microcatheter & Dual-lumen & Length & $\begin{array}{c}\text { Distal shaft outer } \\
\text { diameter }\end{array}$ \\
\hline \multirow[t]{5}{*}{ Asahi Intecc } & Caravel & No & $135 \mathrm{~cm}, 150 \mathrm{~cm}$ & $1.9 \mathrm{Fr}$ \\
\hline & Corsair Pro & No & $135 \mathrm{~cm}, 150 \mathrm{~cm}$ & $2.6 \mathrm{Fr}$ \\
\hline & Corsair Pro XS & No & $135 \mathrm{~cm}, 150 \mathrm{~cm}$ & $2.1 \mathrm{Fr}$ \\
\hline & Sasuke & Yes & $145 \mathrm{~cm}$ & $2.5 \times 3.3 \mathrm{Fr}$ \\
\hline & Tornus & No & $135 \mathrm{~cm}$ & $2.1 \mathrm{Fr}$ and $2.6 \mathrm{Fr}$ \\
\hline \multirow[t]{2}{*}{ Boston Scientific } & Mamba & No & $135 \mathrm{~cm}$ & $2.4 \mathrm{Fr}$ \\
\hline & Mamba Flex & No & $135 \mathrm{~cm}, 150 \mathrm{~cm}$ & $2.1 \mathrm{Fr}$ \\
\hline \multirow[t]{3}{*}{ IMDS } & NHancer Pro X (NX3 and NX6) & No & $135 \mathrm{~cm}, 155 \mathrm{~cm}$ & 2.0 and $2.3 \mathrm{Fr}$ \\
\hline & NHancer Rx & Yes & $135 \mathrm{~cm}$ & $2.3 \times 3.3 \mathrm{Fr}$ \\
\hline & ReCross & Yes (3 exit ports) & $140 \mathrm{~cm}$ & $2.3 \times 3.3 \mathrm{Fr}$ \\
\hline \multirow[t]{2}{*}{ Kaneka } & Crusade & Yes & $140 \mathrm{~cm}$ & $2.9 \mathrm{Fr}$ \\
\hline & Mizuki Standard and Mizuki FX & No & $135 \mathrm{~cm}, 150 \mathrm{~cm}$ & $1.8 \mathrm{Fr}$ and $1.7 \mathrm{Fr}$ \\
\hline \multirow[t]{2}{*}{ Terumo } & Finecross & No & $130 \mathrm{~cm}, 150 \mathrm{~cm}$ & $1.8 \mathrm{Fr}$ \\
\hline & FineDuo & Yes & $140 \mathrm{~cm}$ & $2.9 \mathrm{Fr}$ \\
\hline \multirow[t]{7}{*}{ Teleflex } & SuperCross $\left(45^{\circ}, 90^{\circ}\right.$ or $120^{\circ}$ tip angle) & No & $130 \mathrm{~cm}, 150 \mathrm{~cm}$ & $2.1 \mathrm{Fr}$ \\
\hline & Turnpike & No & $135 \mathrm{~cm}, 150 \mathrm{~cm}$ & $2.6 \mathrm{Fr}$ \\
\hline & Turnpike Spiral & No & $135 \mathrm{~cm}, 150 \mathrm{~cm}$ & $3.1 \mathrm{Fr}$ \\
\hline & Turnpike LP & No & $135 \mathrm{~cm}, 150 \mathrm{~cm}$ & $2.2 \mathrm{Fr}$ \\
\hline & Turnpike Gold & No & $135 \mathrm{~cm}$ & $3.2 \mathrm{Fr}$ \\
\hline & Twin-Pass and Twin-Pass Torque & Yes & $135 \mathrm{~cm}$ & $\begin{array}{c}2.7 \times 3.4 \mathrm{Fr} \text { and } \\
3.5 \times 3.5 \mathrm{Fr}\end{array}$ \\
\hline & Venture & No & $\begin{array}{l}145 \mathrm{~cm} \text { (rapid exchange) } \\
140 \mathrm{~cm} \text { (over-the-wire) }\end{array}$ & $2.2 \mathrm{Fr}$ \\
\hline
\end{tabular}

Asahi Intecc, Aichi, Japan; Boston Scientific Corp., Marlborough, MA, USA; IMDS, Roden, the Netherlands; Kaneka, Tokyo, Japan; Terumo Corp., Tokyo, Japan; Teleflex/Vascular Solutions, Minneapolis, MN, USA. 
called antegrade fenestration and re-entry, has been introduced, wherein multiple fenestrations are created at the level of the distal cap followed by advancement of a polymer-jacketed guidewire from the subintimal space into the distal true lumen $[79,80]$.

In the retrograde approach, the CTO is approached from the donor artery after advancing the guidewire and microcatheter through collaterals [81]. In some cases, it is feasible to cross the occlusion site into the true lumen (retrograde wire escalation technique), followed by guidewire externalization and subsequent conversion to the antegrade approach. In the majority of retrograde cases, however, the reverse controlled antegrade and retrograde tracking (reverse CART) technique has to be applied, wherein the balloon is inflated over the antegrade wire followed by retrograde wiring into the space created by the antegrade balloon, and subsequently the proximal true lumen of the CTO [3].

The integration of the above-mentioned techniques resulted in the concept of the "hybrid algorithm", propagated by the North American operators [82]. Specifically, it is based on the premise that rapid switch of CTO PCl strategies in case of failure increases procedural efficiency. Noteworthy, such an approach is particularly salient in lesions with a high J-CTO score, wherein the chances of antegrade wire escalation fall to $30-40 \%$ [83]. The hybrid algorithm relies on the assessment of 4 angiographic features of CTO (proximal cap ambiguity, quality of the distal vessel, presence of interventional collaterals and occlusion length) that determine the initial $\mathrm{PCl}$ strategy and potential alternative techniques in case of failure. It has been confirmed that the application of the hybrid algorithm enhances procedural success rates ( $90 \%)$ and safety [2]. After introduction of the hybrid algorithm, the Asia Pacific CTO Club algorithm was developed with some modifications (highlighted role of IVUS in proximal cap ambiguity, IVUS-guided wiring as a bailout strategy in the antegrade approach, use of parallel wire technique, use of CrossBoss catheter as a strategy of choice for instent CTO, and lack of CTO length as a determinant for choosing the initial antegrade strategy) [84]. Significantly, in 2019 the EuroCTO Club proposed a modified hybrid algorithm for $\mathrm{CTO} \mathrm{PCl}$, emphasizing the role of antegrade techniques to resolve proximal cap ambiguity (balloon assisted subintimal entry, scratch and go, IVUS-guided puncture) and giving equal relevance to ADR and parallel wire technique after failing antegrade wiring [5].

\section{Cessation of CTO PCI}

It is essential for minimizing complications and lowering the radiation dose to determine conditions for stopping CTO $\mathrm{PCl}$ in case of repeated failures. Hence, it is advocated to stop the procedure when there is no apparent progress of $\mathrm{CTO} \mathrm{PCl}$ and: 1 ) procedural time is $>3 \mathrm{~h}, 2$ ) contrast volume exceeds $4 \times$ the eGFR, or 3 ) the radiation dose is $>5 \mathrm{~Gy}$ [5]. In case of failure and planning a second attempt, CTO PCI should be re-attempted after 6 to 8 weeks. Although re-attempted CTO is associated with higher angiographic complexity as well as longer procedural and fluoroscopy time, in experienced hands the success and complication rates were reported to be similar as compared with the first attempt CTO PCI [85].

\section{Drug-eluting stents and intravascular ultrasound}

Drug-eluting stents are recommended after successful recanalization of CTO so as to reduce the rates of MACE, restenosis and re-occlusion as compared to bare metal stents [5]. While optimal stent sizing and expansion are paramount for improved long-term outcomes (including MACE and definite/probable stent thrombosis), the use of IVUS is particularly advocated in CTO PCI [86-89]. In addition, IVUS plays a pivotal role in the antegrade and retrograde approach for: 1) identification of the proximal cap, 2) antegrade reentry from the subintimal space, 3) retrograde guidewire crossing, 4) reverse CART technique [5]. In the EuroCTO Club database, the use of IVUS in CTO PCI increased from 5\% in 2011 to almost 17\% in 2019 (including $16 \%$ in antegrade and $23 \%$ in retrograde procedures) [90].

\section{Pharmacology during and after procedure}

For achieving optimal periprocedural anticoagulation an initial bolus (100 lU/kg) of intravenous unfractionated heparin (UFH) is routinely administered, and the activated clotting time (ACT) should be monitored every 30 min for the antegrade and every $20 \mathrm{~min}$ for the retrograde approach (optimally a dedicated nurse or a technician is assigned to monitor ACT). An additional bolus of UFH is administered to maintain ACT > 250-300 s during antegrade and $>350$ s during retrograde procedure [5].

Dual antiplatelet therapy (DAPT) for at least 6 months following stenting is currently recommended in patients with stable ischemic heart disease (class I recommendation) [91]. Prolonged (up to 30 months) DAPT duration may be considered (class $\mathrm{ll} b$ recommendation) in patients after complex $\mathrm{PCl}$ [91]. Whereas the optimal duration of DAPT in patients after CTO PCI remains unknown, the tailored approach according to the clinical (diabetes, chronic kidney disease) and angiographic characteristics (e.g. number of stents, stent length, stent diameter) as well as the assessment of bleeding risk should be taken into account [13].

\section{Complications and radiation issues}

Despite the systematic decrease in CTO PCl-related complications, CTO $\mathrm{PCl}$ is associated with higher risk as compared with $\mathrm{PCl}$ of non-occluded coronaries [5]. Particularly, with the prevalence of $2.6-4.8 \%$ coronary perforations are the most common CTO PCI complications [92-94]. Significantly, most perforations occurring during 
CTO $\mathrm{PCl}$ are benign, and can be treated conservatively. The rate of tamponade is significantly lower and accounts for 0.4 to $1.3 \%$ of cases [2, 95]. Additional complications include: access site complications, donor vessel injury, arrhythmias, stroke, contrast-induced nephropathy, radiation dermatitis, emergency bypass grafting and death [96]. The average complication risk in most registries ranges from $0.5 \%$ to $7.0 \%$, but high between-study variability exists $[94,97]$. For example, whereas the rate of death rate was $0 \%$ in the UK Hybrid registry (1 156 patients), $0.2 \%$ and $0.9 \%$ death rates were reported in the EURO-CTO registry (17 626 patients) and OPEN-CTO registry (1 000 patients), respectively $[94,95,98]$. The potential measures to minimize the risk of complications include: 1) dual catheter injection for mitigating the risk of dissection and/or perforation by determination of the guidewire position, 2) placement of safety wire in the CTO donor vessel, 3) maintaining an appropriate ACT level for preventing donor vessel thrombosis, 4) availability of covered stents and coils in case of perforation, 5) proper hydration and limited contrast use (maximal amount of contrast defined as $4 \times$ of the pre-procedural eGFR) [4].

The reduction of the radiation dose encountered during CTO PCI should be the common goal of the whole CTO team. To this end, the ALARA protocol, with the aim of reducing radiation exposure to "As Low As Reasonably Achievable", should be implemented in each catheterization laboratory. Particularly germane to this concept, the basic rules to limit radiation exposure include: 1) use of low-frame rate fluoroscopy and fluoroscopy-store function for documenting balloon and stent inflation instead of cine-angiography, 2) use of collimation, 3) reduction of the distance between the image receptor and the patient, 4) keeping the maximal possible distance from the X-ray lamp, and 5) proper use of protective shields [4, 7].

\section{CTO program and operators' requirements}

Training in such complex procedures as CTO should start after the full understanding and exposure to $\mathrm{PCl}$ in general. Nevertheless, sufficient training in regular $\mathrm{PCl}$ does not automatically translate into an ability to become CTO operator.

High procedural volume is required to achieve and maintain CTO PCI skills $[55,99]$. According to the Euro CTO Club, a large-volume catheterization laboratory with more than 1,000 PCl cases/year can provide continuous training to no more than 1-2 operators in order to exceed the minimal number of $50 \mathrm{CTO}$ PCI cases per year/ per operator. Since it is highly unlikely that the success rate will approach $80 \%$ in lower-volume centers, operators performing less than 30 CTO procedures annually should refer their patients to more experienced operators or involve proctors (particularly in CTO lesions with intermediate and high J-CTO scores) $[5,7]$. It has been shown that while at least $100 \mathrm{CTO} \mathrm{PCl} /$ year must be per- formed by an operator to achieve a success rate $>90 \%$, the minimal number to achieve a success rate $>80 \%$ approximates $50 \mathrm{CTO} \mathrm{PCl/year}[2,5]$. Retrograde techniques should be reserved for experienced operators (preferably those performing $>50$ CTO per year). A minimum of 50 retrograde $\mathrm{CTO} \mathrm{PCl}$ procedures ( 25 as a second operator and 25 as a first operator under supervision) might be advised before a cardiologist becomes an independent retrograde operator [7].

The minimal number of $50 \mathrm{CTO} \mathrm{PCI}$ per year to maintain competency translates into a model where only a limited number of operators and centers should perform CTO revascularization. The basic set of techniques for developing expertise in CTO PCI is represented by antegrade wire escalation and should be followed by implementation of retrograde techniques and ADR. Embracing the retrograde approach requires availability of specific devices (long microcatheters, dedicated wires, guide extensions, snares, etc.), learning several different techniques (from collateral channel engagement to wire externalization) and readiness to deal with complications (e.g. perforation, tamponade, donor vessel ischemia). Regarding collateral channel selection, it might be advisable to start tackling bypass grafts and septal channels first before embarking on retrograde CTO PCI via epicardial collaterals that represent the highest risk for life-threatening complications in case of rupture [5].

\section{Hybrid algorithm according to the Association of Cardiovascular Interventions}

We have provided a modified hybrid algorithm (Figure 2) combining the main features of the original hybrid algorithm by Brilakis et al. and the EuroCTO Club hybrid algorithm [5, 82]. Similar to both of these algorithms we differentiate 3 main characteristics that determine whether the primary approach is antegrade or retrograde: 1) proximal cap ambiguity; 2) quality of the distal vessel; and 3) interventional collaterals. Uniquely, we: 1) specify the fundamental role of adjunctive coronary imaging (including IVUS and/or coronary CTA) as well as dedicated $\mathrm{PCl}$ techniques (balloon-assisted subintimal entry, scratch and go) to resolve proximal cap ambiguity and consequently avoid or improve the efficiency of retrograde procedures; 2) justify the discretionary use of the Crossboss catheter for crossing in-stent CTO; 3) acknowledge that both CTO length and ambiguous vessel course are equally important to dictate the choice of either a wire escalation strategy or a dissection and re-entry strategy; 4) put emphasis on parallel wiring (including IVUS guided re-entry) as a reasonable option after failing antegrade wiring; and 5) define ADR as an equal alternative to antegrade wiring in CTO lesions with clear or resolved proximal cap, occlusion length $\geq 20 \mathrm{~mm}$ and no major bifurcation at the distal cap. In addition, the use of 


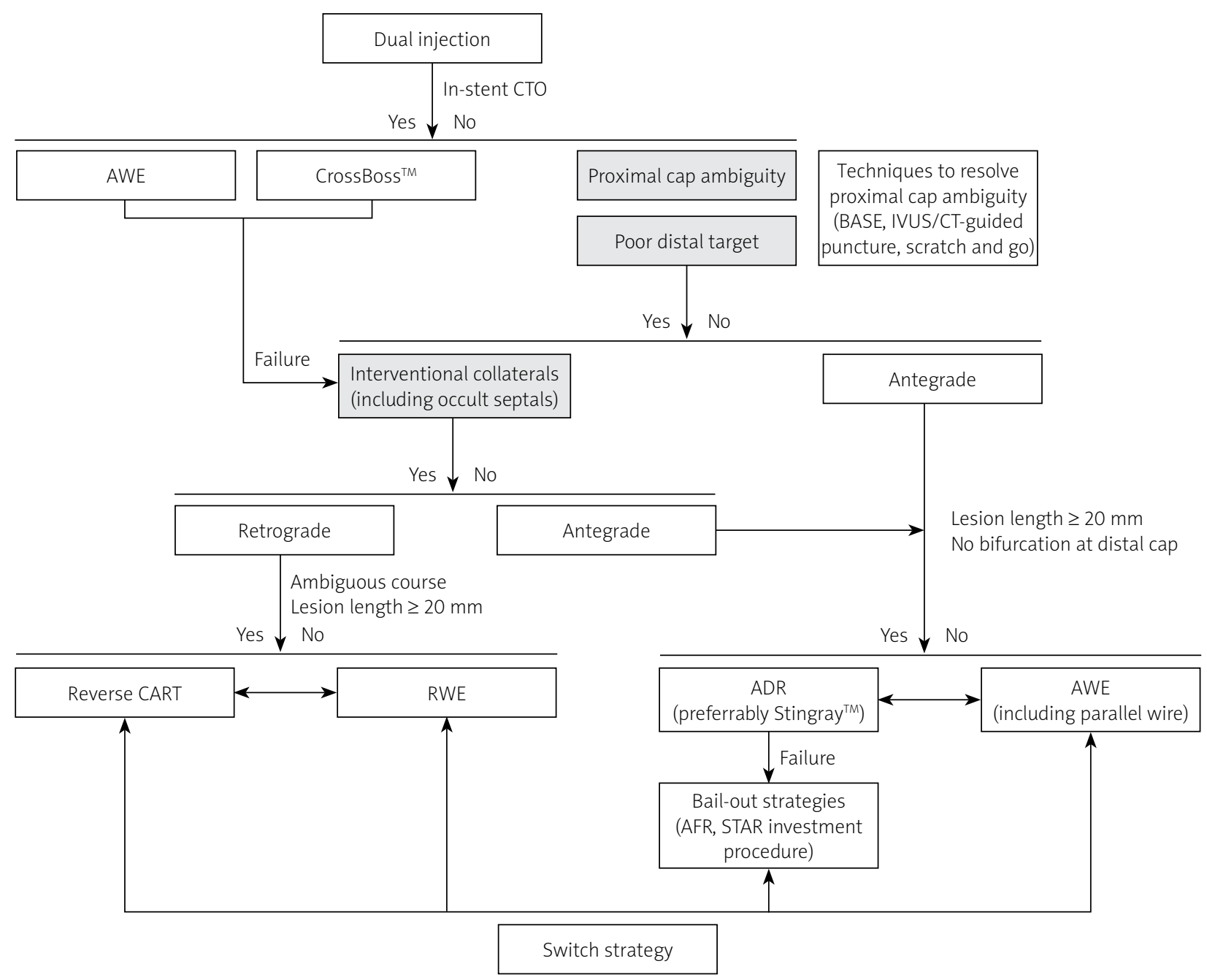

Figure 2. Modified hybrid algorithm for CTO crossing according to the Association of Cardiovascular Interventions of the Polish Cardiac Society

$A D R$ - antegrade dissection and re-entry, AFR - antegrade fenestration and re-entry, AWE - antegrade wire escalation, BASE - balloon-assisted subintimal entry, CART - controlled antegrade retrograde tracking, CT - computed tomography, CTO - chronic total occlusion, IVUS - intravascular ultrasound, $R W E$ - retrograde wire escalation, STAR - subintimal tracking and re-entry.

ADR bail-out strategies (including antegrade fenestration and re-entry) has been underscored.

\section{Reimbursement of CTO PCI}

CTO PCl generally requires more procedural resources, and thus incurs higher procedural costs than regular $\mathrm{PCl}$ of non-CTO vessels. These costs are related to the use of multiple devices such as guiding catheters, guidewires, microcatheters (usually one or two depending on the use of retrograde approach), balloons, drug-eluting stents and closure devices, as well as specialized equipment such as dissection and re-entry catheters (CrossBoss catheter and/or Stingray balloon), guide extension catheters and intravascular ultrasound catheters, and to a lesser frequency atherectomy devices, coils, hemodynamic support devices or snares. This is particularly salient in percutaneous revascularization of CTO using the hybrid approach, wherein dual catheter injection and numerous modern CTO PCI techniques are applied ensuring high success rates exceeding 90\%. Indeed, in a recent cost analysis among 964 patients from the OPEN-CTO registry, the procedural costs of CTO PCI using the hybrid algorithm $(\$ 12,280 \pm 5,972)$ were comparable to the costs of multivessel or left main $\mathrm{PCl}$ in the SYNTAX trial $(\$ 11,919 \pm 6,162)[100,101]$. Noteworthy, these costs did not account for other expenses such as nonprocedural hospital costs $(\$ 3,424 \pm 6,188)$ and physicians' fees $(\$ 1,344 \pm 427)$ that further increase the total cost of CTO PCI in the United States $(\$ 17,048 \pm 9,904)$ [100]. Noteworthy, the total cost of CTO PCI calculated for 10 randomly selected patients from the National Institute of Cardiology in Warsaw in 2019 averaged PLN $15505 \pm 6169$. Nevertheless, the cost of CTO PCI is still far lower than the cost of the alternate method of coronary revascularization, namely coronary artery bypass 
grafting (ranging between $\$ 44,824$ to $\$ 448,038$ ) in the United States [102].

Several countries have already provided higher reimbursement rates for $\mathrm{CTO} \mathrm{PCI}$ than for regular $\mathrm{PCl}$ of nonCTO lesions to account for the additional costs incurred during percutaneous recanalization of CTO. For example, in Germany the reimbursement rate for CTO PCI using either an antegrade or retrograde approach amounts to $€ 4,500$ and exceeds the maximal reimbursement rate for non-CTO $\mathrm{PCI}(€ 3,500)$. Furthermore, in Japan and Singapore separate reimbursement for the devices used during the CTO PCI procedure (microcatheters, guidewires, balloons, stents, etc.) is secured. This is in contrast to the situation in Poland, where all CTO PCI are substantially underestimated and calculated as regular $\mathrm{PCl}$. This, in turn, translates into excess expenditure for the still low number of healthcare providers offering $\mathrm{CTO} \mathrm{PCl}$, and further restrains guideline-recommended interventions among patients with CTO in Poland. The potential solution for this issue at a national level might rely on the institution of CTO PCI reference centers specialized in the most difficult CTO interventions (e.g. in lesions with J-CTO score $\geq 2$ ).

\section{Expert recommendations of the Association of Cardiovascular Interventions}

1. Symptom improvement (including effort angina, dyspnea, and fatigue) is the primary indication for CTO PCl (based on randomized clinical trials). The secondary indications for CTO PCl include improvement of clinical prognosis, increase in left ventricular systolic function and reduction of malignant arrhythmias (based on observational data and expert opinions only).

2. Referral for CTO PCI should be mainly based on clinical grounds (symptoms) as well as ischemia and/or viability assessment. The clinical benefit of CTO PCI should be balanced against the procedural risk related to the specific clinical and angiographic characteristics.

3. Dual coronary angiography and meticulous analysis of the angiogram (and if available coronary CTA) are paramount for planning and safe recanalization of CTO.

4. The use of microcatheters is mandatory to enhance guidewire manipulation and ensure procedural safety.

5. There are 4 main strategies for CTO PCl: antegrade wire escalation, antegrade dissection and re-entry, retrograde wire escalation, and retrograde dissection and re-entry. The full-skilled CTO operator must not only be familiar with all of these techniques, but also quickly change from one technique to another in case of failure.

6. A hybrid algorithm has to be applied when planning and performing CTO recanalization.

7. Radiation and contrast safety issues must be meticulously taken into account when planning and performing CTO recanalization.
8. Dedicated CTO training and adequate procedural volume are essential to ensure high success and low complications rates. Operators embarking on the CTO $\mathrm{PCl}$ training program should start with easy and intermediate CTO lesions (J-CTO score of 0 and 1 ) and involve proctors in more difficult cases (J-CTO score $\geq 2$ ). Centers with a low number of CTO $\mathrm{PCl}$ ( $<30$ yearly) should refer difficult CTO cases to specialized CTO centers. The CTO operator must perform at least 50 procedures annually to maintain skills and reduce the risk of complications.

9. The use of IVUS during CTO PCI is recommended for reduction of the risk of restenosis and re-occlusion and improvement of long-term clinical outcomes.

10. There is unmet need for an adequate number and high quality of CTO procedures in Poland, which are vastly underused due to significant financial constraints.

\section{Summary}

Coronary CTO are increasingly encountered during invasive and non-invasive coronary angiography. Noteworthy, most patients with CTO have inducible ischemia and are symptomatic despite optimal medical therapy, rendering them ideal candidates for coronary revascularization. Historically, based on its angiographic complexity, the presence of CTO was the key driver for coronary artery bypass grafting or medical therapy only. During recent years, however, a clear shift towards percutaneous treatment of CTO has been witnessed, particularly as a result of the unprecedented progress in CTO PCI techniques and equipment as well as specialized training programs of CTO operators. In this regard, high success rates (exceeding $90 \%$ in some luminary centers) along with improved safety outcomes of CTO PCI can be achieved. Significantly, based on randomized clinical trials CTO PCI has been shown to relieve angina and enhance exercise tolerance, translating into improved quality of life. Nevertheless, and contrary to the Western European countries, CTO PCl is significantly underused and accounts for less than $3 \%$ of all $\mathrm{PCl}$ in Poland, leaving many patients with CTO untreated and symptomatic. This mainly results from the barriers in obtaining the adequate skills, tools and training programs among Polish СTO operators as well as non-adequate financial support of CTO procedures in Poland.

The current expert consensus document summarizes the rationale, clinical outcomes as well as technical and safety issues of CTO PCI. Significantly, we have presented a modified hybrid algorithm (the so-called Polish hybrid algorithm) providing some unique refinements to the contemporary CTO PCl strategies. Finally, a list of succinct and practical recommendations on CTO PCI has been provided. Continuous efforts of scientific societies and national associations (including active engagement 
with the payer) are urgently needed to expand CTO PCI knowledge and training programs and close the gap between Poland and Western European countries.

\section{Acknowledgments}

Leszek Bryniarski and Maksymilian P. Opolski contributed equally to this work.

\section{Conflict of interest}

L.B. is a proctor for ProCardia Medical, and received consulting and lecture fees from Boston Scientific, lecture fees from Terumo, lecture fees and travel grants from Medaccess and clinical trial fee from Nitiloop Ltd. M.P.O. is a proctor for ProCardia Medical. J.D. is a proctor for ProCardia Medical, Boston Scientific, Terumo, Medtronic and Biotronik. M.D. is a proctor and advisory board member for Boston Scientific, and received lecture fees from Boston Scientific, Medtronic, Edwards and Abbott. Other authors declare no conflict of interest.

\section{References}

1. Brilakis ES, Banerjee S, Karmpaliotis D, et al. Procedural outcomes of chronic total occlusion percutaneous coronary intervention: a report from the NCDR (National Cardiovascular Data Registry). JACC Cardiovasc Interv 2015; 8: 245-53.

2. Maeremans J, Walsh S, Knaapen P, et al. The hybrid algorithm for treating chronic total occlusions in Europe: The RECHARGE Registry. J Am Coll Cardiol 2016; 68: 1958-70.

3. Galassi AR, Sianos G, Werner GS, et al.; Euro CTO Club. Retrograde recanalization of chronic total occlusions in Europe: procedural, in-hospital, and long-term outcomes from the multicenter ERCTO Registry. J Am Coll Cardiol 2015; 65: 2388-400.

4. Brilakis ES, Mashayekhi K, Tsuchikane E, et al. Guiding principles for chronic total occlusion percutaneous coronary intervention. Circulation 2019; 140: 420-33.

5. Galassi AR, Werner GS, Boukhris M, et al. Percutaneous recanalisation of chronic total occlusions: 2019 consensus document from the EuroCTO Club. Eurolntervention 2019; 15: 198-208.

6. Di Mario C, Werner GS, Sianos G, et al. European perspective in the recanalisation of chronic total occlusions (СТO): consensus document from the EuroCTO Club. Eurolntervention 2007; 3: 30-43.

7. Sianos G, Werner GS, Galassi AR, et al.; EuroCTO Club. Recanalisation of chronic total coronary occlusions: 2012 consensus document from the EuroCTO club. Eurolntervention 2012; 8: 139-45.

8. Råmunddal T, Hoebers LP, Hoebers L, et al. Chronic total occlusions in Sweden: a report from the Swedish Coronary Angiography and Angioplasty Registry (SCAAR). PLoS One 2014; 9: e103850.

9. Tomasello SD, Boukhris M, Giubilato S, et al. Management strategies in patients affected by chronic total occlusions: results from the Italian Registry of Chronic Total Occlusions. Eur Heart J 2015; 36: 3189-98.

10. Jeroudi OM, Alomar ME, Michael TT, et al. Prevalence and management of coronary chronic total occlusions in a tertiary Veterans Affairs hospital. Catheter Cardiovasc Interv 2014; 84: 637-43.
11. Fefer P, Knudtson ML, Cheema AN, et al. Current perspectives on coronary chronic total occlusions: the Canadian Multicenter Chronic Total Occlusions Registry. J Am Coll Cardiol 2012; 59: 991-7.

12. Bryniarski KL, Zabojszcz M, Dębski G, et al. What do Polish interventional cardiologists know about indications and qualification for recanalisation of chronic total coronary artery occlusions? Kardiol Pol 2015; 73: 722-9.

13. Collet JP, Falk V, Head SJ, et al.; ESC Scientific Document Group. 2018 ESC/EACTS Guidelines on myocardial revascularization. Eur Heart J 2019; 40: 87-165.

14. Werner GS, Martin-Yuste V, Hildick-Smith D, et al.; EUROCTO trial investigators. A randomized multicentre trial to compare revascularization with optimal medical therapy for the treatment of chronic total coronary occlusions. Eur Heart J 2018; 39: 2484-93.

15. Mehran R, Claessen BE, Godino C, et al.; Multinational Chronic Total Occlusion Registry. Long-term outcome of percutaneous coronary intervention for chronic total occlusions. JACC Cardiovasc Interv 2011; 4: 952-61.

16. Claessen BE, Dangas GD, Godino C, et al.; Multinational Cto Registry. Long-term clinical outcomes of percutaneous coronary intervention for chronic total occlusions in patients with versus without diabetes mellitus. Am J Cardiol 2011; 108: 924-31.

17. Jones DA, Weerackody R, Rathod K, et al. Successful recanalization of chronic total occlusions is associated with improved long-term survival. JACC Cardiovasc Interv 2012; 5: 380-8.

18. Grantham JA, Jones PG, Cannon L, et al. Quantifying the early health status benefits of successful chronic total occlusion recanalization: results from the FlowCardia's Approach to Chronic Total Occlusion Recanalization (FACTOR) Trial. Circ Cardiovasc Qual Outcomes 2010; 3: 284-90.

19. Joyal D, Afilalo J, Rinfret S. Effectiveness of recanalization of chronic total occlusions: a systematic review and meta-analysis. Am Heart J 2010; 160: 179-87.

20. Obedinskiy AA, Kretov El, Boukhris M, et al. The IMPACTOR-CTO Trial. JACC Cardiovasc Interv 2018; 11: 1309-11.

21. Henriques JPS, Hoebers LP, Råmunddal T, et al.; EXPLORE Trial Investigators. Percutaneous intervention for concurrent chronic total occlusions in patients with STEMI: the EXPLORE trial. J Am Coll Cardiol 2016; 68: 1622-32.

22. Elias J, van Dongen IM, Råmunddal T, et al.; EXPLORE investigators. Long-term impact of chronic total occlusion recanalisation in patients with ST-elevation myocardial infarction. Heart 2018; 104: 1432-8.

23. Lee SW, Lee PH, Ahn JM, et al. Randomized trial evaluating percutaneous coronary intervention for the treatment of chronic total occlusion. Circulation 2019; 139: 1674-83.

24. Brilakis ES, Mashayekhi K, Burke MN. How DECISION-CTO can help guide the decision to perform chronic total occlusion percutaneous coronary intervention. Circulation 2019; 139: 1684-7.

25. Safley DM, Koshy S, Grantham JA, et al. Changes in myocardial ischemic burden following percutaneous coronary intervention of chronic total occlusions. Catheter Cardiovasc Interv 2011; 78: 337-43.

26. Rossello X, Pujadas S, Serra A, et al. Assessment of inducible myocardial ischemia, quality of life, and functional status after successful percutaneous revascularization in patients with chronic total coronary occlusion. Am J Cardiol 2016; 117: 720-6.

27. Azzalini L, Vo M, Dens J, et al. Myths to debunk to improve management, referral, and outcomes in patients with chronic 
total occlusion of an epicardial coronary artery. Am J Cardiol 2015; 116: 1774-80.

28. Mashayekhi K, Neuser H, Kraus A, et al. Successful percutaneous coronary intervention improves cardiopulmonary exercise capacity in patients with chronic total occlusions. J Am Coll Cardiol 2017; 69: 1095-6.

29. Bruckel JT, Jaffer FA, O’Brien C, et al. Angina severity, depression, and response to percutaneous revascularization in patients with chronic total occlusion of coronary arteries. J Invasive Cardiol 2016; 28: 44-51.

30. Christakopoulos GE, Christopoulos G, Carlino M, et al. Metaanalysis of clinical outcomes of patients who underwent percutaneous coronary interventions for chronic total occlusions. Am J Cardiol 2015; 115: 1367-75.

31. Sachdeva R, Agrawal M, Flynn SE, et al. The myocardium supplied by a chronic total occlusion is a persistently ischemic zone. Catheter Cardiovasc Interv 2014; 83: 9-16.

32. Galassi AR, Boukhris M, Toma A, et al. Percutaneous coronary intervention of chronic total occlusions in patients with low left ventricular ejection fraction. JACC Cardiovasc Interv 2017; 10: 2158-70.

33. Mashayekhi K, Nührenberg TG, Toma A, et al. A Randomized trial to assess regional left ventricular function after stent implantation in chronic total occlusion: the REVASC Trial. JACC Cardiovasc Interv 2018; 11: 1982-91.

34. Nombela-Franco L, Mitroi CD, Fernández-Lozano I, et al. Ventricular arrhythmias among implantable cardioverter-defibrillator recipients for primary prevention: impact of chronic total coronary occlusion (VACTO Primary Study). Circ Arrhythm Electrophysiol 2012; 5: 147-54.

35. Nombela-Franco L, lannaccone M, Anguera I, et al. Impact of chronic total coronary occlusion on recurrence of ventricular arrhythmias in ischemic secondary prevention implantable cardioverter-defibrillator recipients (VACTO Secondary Study): insights from coronary angiogram and electrogram analysis. JACC Cardiovasc Interv 2017; 10: 879-88.

36. Di Marco A, Paglino G, Oloriz T, et al. Impact of a chronic total occlusion in an infarct-related artery on the long-term outcome of ventricular tachycardia ablation. J Cardiovasc Electrophysiol 2015; 26: 532-9.

37. O'Connor SA, Garot P, Sanguineti F, et al. Meta-analysis of the impact on mortality of noninfarct-related artery coronary chronic total occlusion in patients presenting with ST-segment elevation myocardial infarction. Am J Cardiol 2015; 116: 8-14.

38. Watanabe H, Morimoto T, Shiomi H, et al. Chronic total occlusion in a non-infarct-related artery is closely associated with increased five-year mortality in patients with ST-segment elevation acute myocardial infarction undergoing primary percutaneous coronary intervention (from the CREDO-Kyoto AMI registry). Eurolntervention 2017; 12: e1874-82.

39. Gierlotka M, Tajstra M, Gąsior M, et al. Impact of chronic total occlusion artery on 12-month mortality in patients with nonST-segment elevation myocardial infarction treated by percutaneous coronary intervention (from the PL-ACS Registry). Int J Cardiol 2013; 168: 250-4.

40. Villablanca PA, Olmedo W, Weinreich M, et al. Staged percutaneous intervention for concurrent chronic total occlusions in patients with ST-segment-elevation myocardial infarction: a systematic review and meta-analysis. J Am Heart Assoc 2018; 7: e008415.
41. Yang JH, Kim BS, Jang WJ, et al. Optimal medical therapy vs. percutaneous coronary intervention for patients with coronary chronic total occlusion - a propensity-matched analysis. Circ J 2016; 80: 211-7.

42. Jang WJ, Yang JH, Choi SH, et al. Long-term survival benefit of revascularization compared with medical therapy in patients with coronary chronic total occlusion and well-developed collateral circulation. JACC Cardiovasc Interv 2015; 8: 271-9.

43. Iannaccone M, D'ascenzo F, Piazza F, et al. Optimal medical therapy vs. coronary revascularization for patients presenting with chronic total occlusion: a meta-analysis of randomized controlled trials and propensity score adjusted studies. Catheter Cardiovasc Interv 2019; 93: E320-5.

44. Garcia S, Sandoval Y, Roukoz H, et al. Outcomes after complete versus incomplete revascularization of patients with multivessel coronary artery disease: a meta-analysis of 89,883 patients enrolled in randomized clinical trials and observational studies. J Am Coll Cardiol 2013; 62: 1421-31.

45. Escaned J, Collet C, Ryan N, et al. Clinical outcomes of stateof-the-art percutaneous coronary revascularization in patients with de novo three vessel disease: 1 -year results of the SYNTAX II study. Eur Heart J 2017; 38: 3124-34.

46. Goel PK, Khanna R, Pandey CM, et al. Long-term outcomes post chronic total occlusion intervention-implications of completeness of revascularization. J Interv Cardiol 2018; 31: 293-301.

47. Toma A, Stähli BE, Gick M, et al. Impact of multi-vessel versus single-vessel disease on outcomes after percutaneous coronary interventions for chronic total occlusions. Clin Res Cardiol 2017; 106: 428-35.

48. Werner GS, Ferrari M, Heinke S, et al. Angiographic assessment of collateral connections in comparison with invasively determined collateral function in chronic coronary occlusions. Circulation 2003; 107: 1972-7.

49. Morino Y, Abe M, Morimoto T, et al.; J-CTO Registry Investigators. Predicting successful guidewire crossing through chronic total occlusion of native coronary lesions within 30 minutes: the J-CTO (Multicenter CTO Registry in Japan) score as a difficulty grading and time assessment tool. JACC Cardiovasc Interv 2011; 4: 213-21.

50. Tanaka H, Morino Y, Abe M, et al. Impact of J-CTO score on procedural outcome and target lesion revascularisation after percutaneous coronary intervention for chronic total occlusion: a substudy of the J-CTO Registry (Multicentre CTO Registry in Japan). Eurolntervention 2016; 11: 981-8.

51. Christopoulos G, Kandzari DE, Yeh RW, et al. Development and validation of a novel scoring system for predicting technical success of chronic total occlusion percutaneous coronary interventions: the PROGRESS CTO (Prospective Global Registry for the Study of Chronic Total Occlusion Intervention) Score. JACC Cardiovasc Interv 2016; 9: 1-9.

52. Maeremans J, Spratt JC, Knaapen P, et al. Towards a contemporary, comprehensive scoring system for determining technical outcomes of hybrid percutaneous chronic total occlusion treatment: the RECHARGE score. Catheter Cardiovasc Interv 2018; 91: 192-202.

53. Alessandrino G, Chevalier B, Lefèvre T, et al. A clinical and angiographic scoring system to predict the probability of successful first-attempt percutaneous coronary intervention in patients with total chronic coronary occlusion. JACC CardiovasC Interv 2015; 8: 1540-8. 
54. Galassi AR, Boukhris M, Azzarelli S, et al. Percutaneous coronary revascularization for chronic total occlusions: a novel predictive score of technical failure using advanced technologies. JACC Cardiovasc Interv 2016; 9: 911-22.

55. Ellis SG, Burke MN, Murad MB, et al.; CAPS Group. Predictors of successful hybrid-approach chronic total coronary artery occlusion stenting: an improved model with novel correlates. JACC Cardiovasc Interv 2017; 10: 1089-98.

56. Khanna R, Pandey CM, Bedi S, et al. A weighted angiographic scoring model (W-CTO score) to predict success of antegrade wire crossing in chronic total occlusion: analysis from a single centre. Asialntervention 2018; 4: 18-25.

57. Szijgyarto Z, Rampat R, Werner GS, et al. Derivation and validation of a chronic total coronary occlusion intervention procedural success score from the 20,000-patient EuroCTO registry: the EuroCTO (CASTLE) score. JACC Cardiovasc Interv 2019; 12: 335-42.

58. Danek BA, Karatasakis A, Karmpaliotis D, et al. Development and validation of a scoring system for predicting periprocedural complications during percutaneous coronary interventions of chronic total occlusions: the prospective global registry for the study of chronic total occlusion intervention (PROGRESS CTO) complications score. J Am Heart Assoc 2016; 5: e004272.

59. Opolski MP, Achenbach S, Schuhbäck A, et al. Coronary computed tomographic prediction rule for time-efficient guidewire crossing through chronic total occlusion: insights from the CT-RECTOR multicenter registry (Computed Tomography Registry of Chronic Total Occlusion Revascularization). JACC Cardiovasc Interv 2015; 8: 257-67.

60. Yu CW, Lee HJ, Suh J, et al. Coronary computed tomography angiography predicts guidewire crossing and success of percutaneous intervention for chronic total occlusion: Korean multicenter CTO CT registry score as a tool for assessing difficulty in chronic total occlusion percutaneous coronary intervention. Circ Cardiovasc Imaging 2017; 10: e005800.

61. Opolski MP, Achenbach S. CT Angiography for revascularization of CTO: crossing the borders of diagnosis and treatment. JACC Cardiovasc Imaging 2015; 8: 846-58.

62. Bakker EJ, Maeremans J, Zivelonghi C, et al. Fully transradial versus transfemoral approach for percutaneous intervention of coronary chronic total occlusions applying the hybrid algorithm: insights from RECHARGE registry. Circ Cardiovasc Interv 2017; 10: e005255.

63. Galassi AR, Tomasello SD, Reifart N, et al. In-hospital outcomes of percutaneous coronary intervention in patients with chronic total occlusion: insights from the ERCTO (European Registry of Chronic Total Occlusion) registry. Eurolntervention 2011; 7: 472-9.

64. Suzuki Y, Tsuchikane E, Katoh O, et al. Outcomes of percutaneous coronary interventions for chronic total occlusion performed by highly experienced japanese specialists: the first report from the Japanese CTO-PCI Expert Registry. JACC Cardiovasc Interv 2017; 10: 2144-54.

65. Tajti P, Karmpaliotis D, Alaswad K, et al. The hybrid approach to chronic total occlusion percutaneous coronary intervention: update from the PROGRESS CTO Registry. JACC Cardiovasc Interv 2018; 11: 1325-35.

66. Azzalini L, Carlino M, Brilakis ES, et al. Subadventitial techniques for chronic total occlusion percutaneous coronary intervention: the concept of "vessel architecture." Catheter Cardiovasc Interv 2018; 91: 725-34.
67. Colombo A, Mikhail GW, Michev I, et al. Treating chronic total occlusions using subintimal tracking and reentry: the STAR technique. Catheter Cardiovasc Interv 2005; 64: 407-11.

68. Valenti R, Vergara R, Migliorini A, et al. Predictors of reocclusion after successful drug-eluting stent-supported percutaneous coronary intervention of chronic total occlusion. J Am Coll Cardiol 2013; 61: 545-50.

69. Godino C, Latib A, Economou Fl, et al. Coronary chronic total occlusions: mid-term comparison of clinical outcome following the use of the guided-STAR technique and conventional anterograde approaches. Catheter Cardiovasc Interv 2012; 79: 20-7.

70. Hirai T, Grantham JA, Sapontis J, et al.; OPEN CTO Study Group. Impact of subintimal plaque modification procedures on health status after unsuccessful chronic total occlusion angioplasty. Catheter Cardiovasc Interv 2018; 91: 1035-42.

71. Goleski PJ, Nakamura K, Liebeskind E, et al. Revascularization of coronary chronic total occlusions with subintimal tracking and reentry followed by deferred stenting: experience from a high-volume referral center. Catheter Cardiovasc Interv 2019; 93: 191-8.

72. Whitlow PL, Burke MN, Lombardi WL, et al.; FAST-CTOs Trial Investigators. Use of a novel crossing and re-entry system in coronary chronic total occlusions that have failed standard crossing techniques: results of the FAST-CTOs (Facilitated Antegrade Steering Technique in Chronic Total Occlusions) trial. JACC Cardiovasc Interv 2012; 5: 393-401.

73. Karacsonyi J, Tajti P, Rangan BV, et al. Randomized comparison of a CrossBoss first versus standard wire escalation strategy for crossing coronary chronic total occlusions: the CrossBoss first trial. JACC Cardiovasc Interv 2018; 11: 225-33.

74. Karatasakis A, Danek BA, Karacsonyi J, et al. Mid-term outcomes of chronic total occlusion percutaneous coronary intervention with subadventitial vs. intraplaque crossing: a systematic review and meta-analysis. Int J Cardiol 2018; 253: 29-34.

75. Walsh SJ, Hanratty CG, McEntegart M, et al. Intravascular healing is not affected by approaches in contemporary CTO $\mathrm{PCl}$ : the CONSISTENT CTO Study. JACC Cardiovasc Interv 2020; 13: 1448-57.

76. Galassi AR, Boukhris M, Tomasello SD, et al. Long-term clinical and angiographic outcomes of the mini-STAR technique as a bailout strategy for percutaneous coronary intervention of chronic total occlusion. Can J Cardiol 2014; 30: 1400-6.

77. Wilson W, Spratt JC. Advances in procedural techniques: antegrade. Curr Cardiol Rev 2014; 10: 127-44.

78. Carlino M, Godino C, Latib A, et al. Subintimal tracking and re-entry technique with contrast guidance: a safer approach. Catheter Cardiovasc Interv 2008; 72: 790-6.

79. Carlino M, Azzalini L, Mitomo S, et al. Antegrade fenestration and re-entry: a new controlled subintimal technique for chronic total occlusion recanalization. Catheter Cardiovasc Interv 2018; 92: 497-504.

80. Azzalini L, Alaswad K, Uretsky BF, et al. Multicenter experience with the antegrade fenestration and reentry technique for chronic total occlusion recanalization. Catheter Cardiovasc Interv 2021; 97: E40-50.

81. Joyal D, Thompson CA, Grantham JA, et al. The retrograde technique for recanalization of chronic total occlusions: a step-bystep approach. JACC Cardiovasc Interv 2012; 5: 1-11. 
82. Brilakis ES, Grantham JA, Rinfret S, et al. A percutaneous treatment algorithm for crossing coronary chronic total occlusions. JACC Cardiovasc Interv 2012; 5: 367-79.

83. Christopoulos G, Wyman RM, Alaswad K, et al. Clinical utility of the japan-chronic total occlusion score in coronary chronic total occlusion interventions: results from a multicenter registry. Circ Cardiovasc Interv 2015; 8: e002171.

84. Harding SA, Wu EB, Lo S, et al. A new algorithm for crossing chronic total occlusions from the Asia Pacific Chronic Total Occlusion Club. JACC Cardiovasc Interv 2017; 10: 2135-43.

85. Karacsonyi J, Karatasakis A, Karmpaliotis D, et al. Effect of previous failure on subsequent procedural outcomes of chronic total occlusion percutaneous coronary intervention (from a Contemporary Multicenter Registry). Am J Cardiol 2016; 117 : 1267-71.

86. Tian NL, Gami SK, Ye F, et al. Angiographic and clinical comparisons of intravascular ultrasound- versus angiography-guided drug-eluting stent implantation for patients with chronic total occlusion lesions: two-year results from a randomised AIR-CTO study. Eurolntervention 2015; 10: 1409-17.

87. Kim BK, Shin DH, Hong MK, et al.; CTO-IVUS Study Investigators. Clinical impact of intravascular ultrasound-guided chronic total occlusion intervention with zotarolimus-eluting versus biolimus-eluting stent implantation: randomized study. Circ Cardiovasc Interv 2015; 8: e002592.

88. Darmoch F, Alraies MC, Al-Khadra Y, et al. Intravascular ultrasound imaging-guided versus coronary angiography-guided percutaneous coronary intervention: a systematic review and meta-analysis. J Am Heart Assoc 2020; 9: e013678.

89. Kim D, Hong SJ, Kim BK, et al. Outcomes of stent optimisation in intravascular ultrasound-guided interventions for long lesions or chronic total occlusions. Eurolntervention 2020; 16 : e480-8.

90. Available at: https://www.eurocto.eu/slides/en-GB/1055/updatedata-registry. Assessed September 8, 2020.

91. Valgimigli M, Bueno H, Byrne RA, et al.; ESC Scientific Document Group, ESC Committee for Practice Guidelines (CPG), ESC National Cardiac Societies. 2017 ESC focused update on dual antiplatelet therapy in coronary artery disease developed in collaboration with EACTS: The Task Force for dual antiplatelet therapy in coronary artery disease of the European Society of Cardiology (ESC) and of the European Association for Cardio-Thoracic Surgery (EACTS). Eur Heart J 2018; 39: 213-60.

92. Galassi AR, Tomasello SD, Reifart N, et al. In-hospital outcomes of percutaneous coronary intervention in patients with chronic total occlusion: insights from the ERCTO (European Registry of Chronic Total Occlusion) registry. Eurolntervention 2011; 7: 472-9.

93. Danek BA, Karatasakis A, Tajti P, et al. Incidence, treatment, and outcomes of coronary perforation during chronic total occlusion percutaneous coronary intervention. Am J Cardiol 2017; 120: 1285-92.

94. Sapontis J, Salisbury AC, Yeh RW, et al. Early procedural and health status outcomes after chronic total occlusion angioplasty: a report from the OPEN-CTO Registry (Outcomes, Patient Health Status, and Efficiency in Chronic Total Occlusion Hybrid Procedures). JACC Cardiovasc Interv 2017; 10: 1523-34.

95. Konstantinidis NV, Werner GS, Deftereos S, et al.; Euro CTO Club. Temporal trends in chronic total occlusion interventions in Europe. Circ Cardiovasc Interv 2018; 11: e006229.
96. Wu EB, Tsuchikane E. The inherent catastrophic traps in retrograde CTO PCI. Catheter Cardiovasc Interv 2018; 91: 1101-9.

97. Habara M, Tsuchikane E, Muramatsu T, et al.; Retrograde Summit Investigators. Comparison of percutaneous coronary intervention for chronic total occlusion outcome according to operator experience from the Japanese retrograde summit registry. Catheter Cardiovasc Interv 2016; 87: 1027-35.

98. Wilson WM, Walsh SJ, Yan AT, et al. Hybrid approach improves success of chronic total occlusion angioplasty. Heart 2016; 102: 1486-93.

99. Kinnaird T, Gallagher S, Cockburn J, et al.; British Cardiovascular Intervention Society and the National Institute for Cardiovascular Outcomes Research. Procedural success and outcomes with increasing use of enabling strategies for chronic total occlusion intervention. Circ Cardiovasc Interv 2018; 11: e006436.

100. Salisbury AC, Karmpaliotis D, Grantham JA, et al. In-hospital costs and costs of complications of chronic total occlusion angioplasty: insights from the OPEN-CTO Registry. JACC Cardiovasc Interv 2019; 12: 323-31.

101. Serruys PW, Morice MC, Kappetein AP, et al. Percutaneous coronary intervention versus coronary-artery bypass grafting for severe coronary artery disease. N Engl J Med 2009; 360: 961-72.

102. Giacomino BD, Cram P, Vaughan-Sarrazin M, et al. Association of hospital prices for coronary artery bypass grafting with hospital quality and reimbursement. Am J Cardiol 2016; 117 : 1101-6. 